\title{
SIG NA ANÁLISE DO RISCO DE SALINIZAÇÃO NA BACIA DO RIO CORURIPE, AL.
}

\author{
Gustavo Souza Valladares ${ }^{1}$ \\ André Luiz Lopez Faria ${ }^{2}$
}

\begin{abstract}
Resumo: Visando orientar o plano de manejo da Bacia do Rio Coruripe, AL, o presente trabalho objetivou gerar um mapa de risco de salinização na escala 1:100.000, com resolução espacial de 50 metros. O mapa foi gerado do tratamento das imagens digitalizadas dos temas solos, geomorfologia e geologia, no SAGA (Sistema de Análise Geo-Ambiental), que é um Sistema Geográfico de Informação (SIG). Foram geradas seis classes de risco de salinização, onde $7,9 \%$ da área corresponde à classe de risco muito baixo de salinização, $22,5 \%$ risco baixo, 30,5\% moderado, 36,8\% alto, 0,4\% risco muito alto e $0,3 \%$ altíssimo. A metodologia utilizada foi eficiente na geração do mapa de risco de salinização da Bacia do Rio Coruripe.
\end{abstract}

Palavras-Chave: geoprocessamento, mapa, semi-árido, pedologia

Abstract: To guide the plan of handling for the River Coruripe Basin, AL, the present work objectified to generate a risk of salinization map in scale 1:100,000, with 50 meters of spatial resolution. Such map was generated from the treatment of the digital images of soils, geomorphology and geology, in the SAGA (System of Geo-Environmental Analysis), which is a Geographic Information System (GIS). Six classes of salinization risk had been generated, where $7.9 \%$ of the area correspond the class very low risk of salinization, $22.5 \%$ low risk, moderate $30.5 \%$, high $36.8 \%$, $0.4 \%$ very high risk and the highest $0.3 \%$. The used methodology was efficient to generate a risk of salinization map for the River Coruripe Basin.

Key-words: geoprocessing, map, salinization.

\section{DESERTIFICAÇÃO}

A desertificação é definida na Agenda 21, que visa atingir um novo padrão de desenvolvimento, conciliando métodos de proteção ambiental, justiça social e eficiência econômica (MINISTÉRIO DO MEIO AMBIENTE, 2004), como a degradação do solo nas zonas áridas, semi-áridas e sub-úmidas secas resultantes de fatores diversos tais como as variações climáticas e as atividades humanas (IPCC, 1999; Accioly, 2000; MMA, s.d.; Schofield; Kirby, 2003). Segundo Corrêa (1999), a cerca de um século foi citada a ação antrópica gerando desertificação e degradação dos recursos naturais do
Nordeste. No entanto, apenas na década de 30, com a destruição dos solos e da vegetação que ocorreu no Meio Oeste americano, que o problema foi caracterizado de forma mais completa. (Ambientebrasil, s.d.).

Em vários continentes como, América Latina, Ásia, Europa, África e Continente Australiano, o inadequado e intensivo uso do solo levou à destruição de recursos naturais e transformou áreas férteis em desertos ecológico-econômicos (Ambientebrasil, s.d.), sendo a desertificação tema de vários trabalhos (Slavnyi \& Mel'Nikova, 1977; Oyama \& Nobre, 2003; Symeonakis \& Drake, 2004). Atualmente, a desertificação ocorre em mais de 100 países do mundo

\footnotetext{
${ }^{1}$ Embrapa Monitoramento por Satélite, gustavo@cnpm.embrapa.br.

${ }^{2}$ Curso de Geografia da Faculdade de Filosofia, Ciências e Letras de Além Paraíba, farial@terra.com.br
} 
e, por isso, é considerado um problema global.

No Brasil as terras susceptíveis ao processo da desertificação são aquelas situadas na região semi-árida nordestina e correspondem a, aproximadamente, 11\% do território brasileiro (MMA, s.d.). O trópico semi-árido, conforme definição da SUDENE, compreende uma área de $980.711 \mathrm{~km}^{2}$, distribuídos em oito estados do Nordeste e no norte de Minas Gerais. O semi-árido apresenta grande diferenciação ecológica, com secas e estiagens afetando quase a totalidade da atividade agropecuária e, mais acentuadamente, as pequenas e médias propriedades, provocando graves problemas sócio-econômicos e migrações em massa para outras partes do País (MMA, s.d.).

AB'Saber 1977 (I: Suetegary 1996), afirma que o ambiente frágil do nordeste se apresenta em processo de desertificação, em decorrência da estrutura geo-ecológica e, na maior parte das vezes, intensificada por ações antrópicas diretas e indiretas.

Segundo a EMBRAPA 1994 (Suertegary 1996), pode-se localizar processo de desertificação em várias regiões do Brasil, dentre elas: região nordeste (semi-árido nordestino), cujas causas da desertificação estão associadas ao desmatamento, a mineração, ao sobrepastoreio, ao cultivo excessivo, a irrigação inadequada e ao latifúndio; região sul e neste particular a citação feita refere-se ao sudoeste do Rio Grande do Sul; região norte/Amazônia onde é admitida que a agricultura praticada poderá abrir caminho à desertificação.

Nas áreas onde ocorrem os impactos difusos, os danos ambientais produzidos resultam em erosão dos solos, empobrecimento da caatinga e degradação dos recursos hídricos, com efeitos diretos sobre a qualidade de vida da população. Já nas áreas onde os efeitos estão concentrados em pequena parte do território, os danos ocorrem com profunda gravidade, configurando o que se chama de Núcleo Desertificado. Os estudos permitiram uma identificação inicial de quatro Núcleos, onde a desertificação pode ser considerada extremamente grave, com forte comprometimento dos recursos naturais. São eles: Gilbués/PI, Irauçuba/CE, Seridó/RN/PB, Cabrobó/PE, cuja área total é de cerca de $15.000 \mathrm{~km}^{2}$ (MMA, s.d.). Estima-se que o processo de desertificação na região semi-árida vem comprometendo seriamente uma área de $181.000 \mathrm{~km}^{2}$, com a geração de impactos difusos e concentrados sobre o território (Coimbra, 2002).

\section{SALINIZAÇÃO}

Para Faria 2001, a preservação e recuperação dos recursos naturais deve ser realizada de maneira integrada. A unidade ideal para programação do uso e manejo dos recursos naturais é a bacia hidrográfica, que é definida como a região de contribuição para um determinado curso d'água. Ao se investigar uma bacia deve-se efetuar seu diagnóstico ambiental, fazendo parte do mesmo o levantamento de seu meio físico, como: solos, geomorfologia, litologia etc.. Na definição do plano de manejo de uma determinada área, tornase importante a interpretação de inventários do meio físico, como por exemplo mapas de riscos, com objetivo de conservação dos recursos naturais. Tais mapas de riscos devem ser adequados à realidade local, como no presente trabalho que gerou um mapa de risco de salinização para a bacia do Rio Coruripe, Estado de Alagoas.

A agricultura irrigada está transformando a economia do semi-árido nordestino. Quando se compara a receita do cultivo irrigado com o cultivo dependente de chuva observa-se que ela é cerca de dez vezes superior em anos normais. Estimulada enquanto política de desenvolvimento rural a partir da década de 70, a agricultura irrigada já está instalada em cerca de 600 mil ha da região. A irrigação tornou o ambiente nordestino vantajoso se comparado com outras regiões brasileiras, porque dispõem de insolação durante cerca de oito meses do ano e apresenta clima quente e seco, aliados essenciais da 
produção irrigada de frutas e hortaliças de qualidade. A geração de tecnologias pelo setor privado e pelo setor público para o ambiente semi-árido tem conseguido sintetizar negócios agrícolas gerados com a irrigação (Embrapa Semiárido, s.d.).

Porém, o planejamento deficiente e o manejo inadequado da irrigação em diversos pontos da região Nordeste têm conduzido, em médio ou longo prazo, a problemas de salinidade do solo ou de elevação do lençol freático a níveis críticos. Em ambos os casos a produtividade da atividade agrícola é comprometida e os danos ambientais são severos. É um problema sério e as tecnologias e informações que $o$ solucionam são base estruturadora de projetos de irrigação de caráter público ou privado (Embrapa Semi-árido, s.d.). A irrigação mal conduzida provoca a salinização dos solos, inviabilizando algumas áreas e perímetros irrigados do semi-árido (Accioly, 2000), o problema tem sido provocado tanto pelo tipo de sistema de irrigação, muitas vezes inadequado às características do solo, quanto pela maneira como a atividade é executada, fazendo mais uma "molhação" do que irrigando.

Segundo o Sistema Brasileiro de Classificação de Solos (Embrapa, 1999) caráter sódico é utilizado para distinguir horizontes ou camadas do solo que apresentem saturação por sódio $\geq 15 \%$ e solódico variando de 6 a $<15 \%$. Solos com caráter sálico são caracterizados por condutividade elétrica no extrato saturado maior ou igual que $7 \mathrm{dS} / \mathrm{m}$ (a $25^{\circ} \mathrm{C}$ ) e salino com valores entre 4 e $7 \mathrm{dS} / \mathrm{m}$. Segundo Ramalho \& Beek (1995) condutividade elétrica do solo entre 4 e 8 e saturação por sódio entre 8 e $20 \%$, já representam grau de limitação moderado à agricultura por deficiência de fertilidade; a condutividade elétrica entre 8 e 15 e a saturação por sódio superior a $15 \%$ indicam forte limitação ao desenvolvimento vegetal.

Macêdo \& Santos (1992) estudando solos irrigados na bacia Sucuru/Sumé, PB com água salina, verificaram que a salinidade natural dos solos e o uso contínuo da irrigação aumentaram o risco de salinização, sendo que uma forma para melhorar a qualidade da água foi a utilização de gesso agrícola. No perímetro irrigado de Custódia, PE, solos aluviais tiveram seu processo de uso agrícola interrompido por problemas de salinidade e sodicidade, causado principalmente pela baixa qualidade da água de irrigação (Oliveira et al., 2002). Segundo os autores a reutilização desses solos para irrigação deve ser precedida com o uso de corretivos e de eficientes sistemas de drenagem.

Silva et al. (1998) estudando os solos e culturas em áreas com barragens subterrâneas em Petrolina, PE, verificaram que após oito anos de cultivo as áreas tiveram baixo risco de salinização e permitiram a utilização dos solos com culturas perenes e anuais, sem haver queda da produtividade, demonstrando que essa tecnologia pode ser interessante para o semi-árido brasileiro.

Pelas características naturais das regiões secas, susceptíveis à desertificação, seu desenvolvimento não deve ser baseado em modelos dos trópicos úmidos ou de áreas de clima temperado, pois exigem investimentos maiores e por tempo prolongado. Portanto, nessas áreas, devem ser prioritários o controle demográfico e o incentivo a projetos de pequeno porte e de abrangência reduzida, ao invés de grandes projetos complexos, normalmente com elevado nível de impacto (Mainguet; Silva, 1998).

Oliveira (1996) destaca que as seguintes medidas poderiam ser tomadas para reduzir os processos de salinização e sodificação dos solos:

Melhoria dos sistemas de drenagem; observações periódicas do nível do lençol freático; análises periódicas do solo e das águas de irrigação e do lençol freático; uso de práticas agrícolas adequadas e de culturas selecionadas em função de suas tolerâncias à salinidade; assistência técnica permanente aos irrigantes.

Dentre os objetivos da Política Nacional de Controle da Desertificação 
(CONAMA, 1997) enquadra-se a formulação de propostas para a gestão ambiental e o uso dos recursos naturais existentes na caatinga e áreas de transição, sem comprometê-los em longo prazo. Esse enfoque também deve levar em conta a prevenção e a recuperação das áreas atualmente afetadas e, para tanto, são necessários estudos de identificação precoce das áreas em processo de desertificação. Nesse tipo de abordagem o sensoriamento remoto configura-se como uma ferramenta de grande importância (Mainguet; Silva, 1998; Bastos et al., 2000; Torrion, 2002; Symeonakis; Drake, 2004), servindo de base para o componente 6 da Estratégia Nacional de Controle da Desertificação, referente à elaboração de estratégias de monitoramento da desertificação.

$\mathrm{Na}$ Bacia Hidrográfica do Rio Coruripe encontram-se dois processos principais que podem conduzir à salinização dos solos: a influência marinha nas regiões costeiras; e na região do Agreste, por exemplo, em Palmeira dos Índios, que apresenta déficit hídrico, com a evapotranspiração maior do que a precipitação entre os meses de agosto e abril (Sentelhas et al., 2003), o que representa $75 \%$ do período anual, os sais presentes na solução do solo ascendem pelo processo de evaporação da água, levando a uma concentração de sais na superfície do solo, sendo comuns os solos com caráter solódico naquela região (Jacomine et al., 1975).

Associado aos fatores acima, as características físico-químicas e biológicas do solo, bem como as características físicas do meio natural (Geomorfologia e Geologia) influenciam no processo de salinização.

\section{OBJETIVOS}

O presente trabalho objetivou gerar um mapa de riscos de salinização para a bacia do Rio Coruripe, que posteriormente pode ser utilizado no planejamento agroambiental da bacia, indicando utilização apropriada aos solos, visando sua conservação e a sustentabilidade dos sistemas de produção.

\section{MATERIAL E MÉTODOS}

A Bacia do Rio Coruripe localizase no Estado de Alagoas está compreendida entre as coordenadas $36^{\circ} \mathrm{e}$ $37^{\circ} \mathrm{WGr}$ e $9^{\circ} 20^{\prime}$ e $10^{\circ} 20^{\prime} \mathrm{S}$. Suas nascentes localizam-se na região de Palmeira dos Índios na região do agreste com clima semi-árido segundo a classificação de Köppen dos tipos BSs'h' e BSsh' (Jacomine et al., 1975) e sua foz no Oceano Atlântico fica na região de Coruripe na Zona da Mata com clima As'. A bacia tem uma forma alongada paralela ao Rio São Francisco, com a maior distância de aproximadamente $110 \mathrm{~km}$, com uma grande variabilidade de clima, vegetação nativa, solos, geologia e geomorfologia. $\mathrm{O}$ uso predominante na área é a agropecuária, com a cultura da cana-de-açúcar na zona da mata e da pecuária extensiva com culturas de subsistência no agreste.

Foram gerados mapas temáticos (solos, geomorfologia e litologia) da área em estudo. A partir da análise de imagem de radar na escala 1:250.000 - Projeto Radam Brasil, foi realizado uma fotointerpretação para identificação e caracterização das formas de relevo. Utilizou-se ainda as Fotografias Aéreas da Superintendência para Desenvolvimento do Nordeste na Escala de 1: 70.000 Faixas - 02 Fotos de 491 à 498; 04 Fotos de 832 à 840; 04 Fotos de 867 à 860; 04 Fotos de 900 à 902 e Fotografias Aéreas da Petrobras DEXPRO, região de Sergipe/Alagoas na escala 1:60.000 Fotos: 111 a 112; 128 à 131; 213 à 215; 225 à 226; 244 à 246. Para identificação das unidades de solo e geomorfologia, foram utilizados: tonalidade, forma, textura, tamanho da forma e padrão de drenagem. As unidades mapeadas em papéis transparentes foram colocadas sobre a base planialtimétrica na escala 1:100.000. Foram feitas ampliações e reduções na escala, para compatibilizar a escala da imagem de radar, das fotografias aéreas com a escala de trabalho. 
Para o mapa de solos foi feita compilação do levantamento exploratório - reconhecimento realizado na escala 1:400.000 (Jacomine et al., 1975), como também checagens de campo e nova delimitação das unidades de mapeamento, adequando-as a escala do trabalho; os perfis das unidades de mapeamento tiveram sua classificação atualizada segundo o Sistema Brasileiro de Classificação de Solos (Embrapa, 1999). O mapa de litologia foi elaborado por compilação do mapa do Programa Levantamentos Geológicos do Brasil, Arapiraca folha SC.24-X-D-V, AL (CPRM, 1995) e do Projeto Baixo São Francisco / Vaza-barris, folhas SC.24-XD e SC.24-Z-B (CPRM, 1977).

Foi utilizada a estrutura matricial "RASTER" para a montagem da Base de Dados Georreferenciada. A entrada de dados de caráter espacial foi realizada através de leitura ótica por "SCANNER", que consistiu na leitura e captura dos registros espaciais. A fase operacional, seguinte à edição dos dados,, foi procedida pelo reconhecimento das feições geométricas, realizadas pelo processo de vetorização interativa nestes dados digitalizados. Os mapas foram tratados em Sistema Geográfico de Informação (SIG) denominado SAGA (Sistema de Análise Geo-Ambiental), desenvolvido pelo laboratório de Geoprocessamento (LAGEOP) do Departamento de Geografia da UFRJ. As imagens dos mapas de solos, geomorfologia e litologia foram tratadas no SAGA, através de avaliações e assinaturas, gerando o mapa de risco de salinização na escala 1:100.000 com resolução de 50 metros. A legenda do mapa foi a seguinte: muito baixo, baixo, moderado, alto, muito alto e altíssimo risco de salinização. A técnica de geoprocessamento permitiu o tratamento dos dados, desde a sua entrada, passando pela edição, armazenamento e, finalmente, as análises ambientais, com a extração das informações registradas nos cartogramas digitais.

Para Xavier-da-Silva (1992), "o uso do Sistema Geográfico de Informação permite ganhar conhecimento sobre as relações entre fenômenos ambientais", estimando áreas de risco, potenciais ambientais e definindo zoneamentos.

O mapa foi gerado com o uso de um método multicritério aditivo, definido por Xavier-da-Silva (2000) como média ponderada. A integração entre SIG e Apoio Multicritério à Decisão é abordada na literatura (Jankowski, 1995; Malczewski, 1999; Gomes; Estellita Lins, 2002)

Um algoritmo sugerido (eq. 1), aplicável a estruturas de matrizes ou matriciais, adequado aos mapas raster utilizados, é apresentado a seguir:

$n$

Aij $=\Sigma($ Pk. Nk) (Eq. 1) sendo: $\mathrm{k}=1$

Aij = qualquer célula da matriz (alternativa);

$\mathrm{n}$ = número de parâmetros envolvidos;

$\mathrm{P}$ = peso atribuído ao parâmetro, transposto o percentual para a escala de 0 a 1 ;

$\mathrm{N}=$ nota na escala de 0 a 10 , atribuída à categoria encontrada na célula.

Para a realização das avaliações, foi empregado o algoritmo classificador, aplicável a uma estrutura de matrizes, no qual cada célula corresponde a uma unidade territorial. A importância de cada evento analisado foi considerada em função do somatório dos produtos dos pesos relativos das variáveis escolhidas, multiplicado pelas notas das classes em cada unidade da célula.

O mapa de risco de salinização foi gerado utilizando o método multicritério citado acima, considerando peso 55\% para o tema (critério) Pedologia, 25\% Geomorfologia e 20\% Geologia. As notas do risco de salinização foram dadas às unidades de mapeamentos dos mapas, numa escala de 0 a 10 , indicando que quanto maior a nota maior o risco de salinização da unidade de mapeamento. Os pesos e notas foram definidos por uma equipe composta por profissionais especialistas em Pedologia, Geomorfologia e Geologia. A definição foi baseada na experiência dos 
profissionais e por consenso entre os mesmos. O maior peso do mapa de pedologia deve-se às informações contidas nesse plano de informação sobre a salinidade natural dos solos, suas propriedades químicas e físicas e as informações da declividade do terreno.

O uso de SIGs permite obter mapas com rapidez e precisão a partir da atualização dos bancos de dados, sendo uma ferramenta importante no estudo de potencialidades do ambiente, e, no caso da avaliação de áreas com risco de salinização constitui-se etapa importante para a definição de práticas adequadas de manejo e conservação do solo e recursos hídricos.

\section{RESULTADOS E DISCUSSÃO}

$\mathrm{Na}$ Bacia do Rio Coruripe, verifica-se uma grande variação dos solos, nas cotas próximas ao nível do mar são verificados solos com fortes influências das marés aparecendo solos com salinidade e tiomorfismo, pertencendo a diferentes ordens, a saber: Espodossolos, Neossolos Quatzarênicos, Gleissolos e Organossolos. No vale do Rio Coruripe na região da zona da mata predominam os Gleissolos, Organossolos e Neossolos Flúvicos. Nos tabuleiros costeiros, apesar dos extensos topos aplainados há grande variabilidade dos solos, aparecem com mais freqüência Argissolos, Latossolos, Plintossolos, Espodossolos e Neossolos Quatzarênicos. Na região do agreste a variabilidade dos solos não é menor, com Planossolos, Latossolos, Argissolos, Nitossolos, Neossolos Litólicos e Chernossolos.

Abaixo são apresentadas as unidades do mapa de solos com a nota para o risco de salinização entre parênteses:

LAx1 (3)- Assoc. de: LATOSSOLO AMARELO Coeso típico + ARGISSOLO AMARELO Distrófico latossólico ambos textura argilosa + ARGISSOLO AMARELO Distrófico ou Eutrófico planossólico fragipânico textura média/argilosa, todos A moderado fase floresta subperenifólia e cerrado relevo plano a suave ondulado.

LAd1 (5)- Assoc. de: LATOSSOLO AMARELO Distrófico argissólico textura média + ARGISSOLO AMARELO Distrófico textura arenosa e média/média e argilosa ambos A moderado e proeminente fase floresta subcaducifólia + PLANOSSOLO HÁPLICO Eutrófico solódico textura arenosa e média/média e argilosa A moderado fase floresta caducifólia, todos fase relevo plano a suave ondulado.

LVe1 (4)- Assoc. de: LATOSSOLO VERMELHO Eutrófico típico + NITOSSOLO VERMELHO

Eutrófico latossólico, ambos textura argilosa A moderado e proeminente fase floresta caducifólia relevo suave ondulado e ondulado.

LVe2 (5)- Assoc. de: LATOSSOLO VERMELHO Eutrófico típico textura média e argilosa + ARGISSOLO VERMELHO Eutrófico plíntico textura média/argilosa fase concrecionária, ambos A moderado e proeminente + PLANOSSOLO HÁPLICO Eutrófico solódico textura arenosa e média/média e argilosa A moderado fase floresta caducifólia, todos fase floresta caducifólia relevo suave ondulado e ondulado.

LVAe1 (4)- Assoc. de: LATOSSOLO VERMELHO-AMARELO Eutrófico argissólico + ARGISSOLO AMARELO Eutrófico abrúptico + LATOSSOLO VERMELHO Eutrófico típico, todos textura média fase floresta caducifólia + PLANOSSOLO HÁPLICO Eutrófico solódico textura arenosa e média/média e argilosa, todos A moderado e fraco fase relevo plano a suave ondulado.

NX1 (4)- Assoc. de: NITOSSOLO HÁPLICO Eutrófico típico textura média/argilosa fase concrecionária e pedregosa floresta caducifólia relevo suave ondulado a forte ondulado + NEOSSOLOS

LITÓLICOS

Eutróficos e Distróficos típicos textura média fase pedregosa e rochosa relevo ondulado e forte 
ondulado substrato gnaisse e quartzito, ambos A proeminente e moderado + PLANOSSOLO HÁPLICO Eutrófico solódico textura arenosa e média/média e argilosa fase floresta caducifólia relevo suave ondulado e ondulado.

NV1 (1)- Assoc. de: NITOSSOLO VERMELHO Eutrófico típico textura argilosa + ARGISSOLO VERMELHO-AMARELO Eutrófico planossólico textura média/argilosa + NEOSSOLOS LITÓLICOS Eutróficos e Distróficos típicos textura média substrato gnaisse e granito, todos A moderado $\mathrm{e}$ proeminente fase floresta subcaducifólia relevo ondulado a montanhoso + Afloramentos de Rocha.

PAd1 (3)- Assoc. de: ARGISSOLO AMARELO Distrófico fragipânico textura média/argilosa + ARGISSOLO AMARELO Distrófico latossólico textura argilosa + LATOSSOLO AMARELO Coeso típico textura argilosa, todos A moderado e proeminente fase floresta subperenifólia relevo plano.

PAd2 (4)- Assoc. de: ARGISSOLO AMARELO Distrófico plíntico textura média/argilosa A moderado e proeminente fase concrecionária + ARGISSOLO AMARELO Distrófico típico textura argilosa A moderado, ambos fase floresta subcaducifólia relevo suave ondulado a forte ondulado + PLANOSSOLO HÁPLICO Eutrófico solódico textura arenosa e média/média e argilosa A moderado fase floresta caducifólia relevo suave ondulado e ondulado.

PAd3 (3)- Assoc. de: ARGISSOLO AMARELO Distrófico fragipânico textura média/argilosa + ARGISSOLO AMARELO Distrófico abrúptico fragipânico textura arenosa/média, ambos A moderado fase cerrado relevo plano.

PAd4 (3)- ARGISSOLO AMARELO

Distrófico fragipânico textura média/argilosa A moderado fase floresta subperenifólia relevo plano e suave ondulado.
PAd5 (2)- ARGISSOLO AMARELO Distrófico típico + LATOSSOLO AMARELO Coeso típico, ambos textura argilosa A moderado fase concrecionária relevo ondulado e forte ondulado + ARGISSOLO AMARELO Distrófico abrúptico plíntico textura arenosa e média/argilosa A moderado fase relevo suave ondulado e ondulado, todos fase floresta subperenifólia.

PAd6 (2)- Assoc. de: ARGISSOLO AMARELO Distrófico abrúptico plíntico textura média/argilosa fase concrecionária + ARGISSOLO AMARELO Distrófico típico textura argilosa, ambos A moderado fase floresta subperenifólia relevo ondulado a montanhoso.

PVe1 (2)- Assoc. de: ARGISSOLO VERMELHO Eutrófico + ARGISSOLO VERMELHOAMARELO, ambos textura média/argilosa + NITOSSOLO VERMELHO Eutrófico típico textura argilosa, ambos A moderado e proeminente fase floresta subcaducifólia relevo ondulado e forte ondulado.

SXe1 (7)- Assoc. de: PLANOSSOLO HÁPLICO Eutrófico solódico textura arenosa e média/média e argilosa A moderado + ARGISSOLO VERMELHO Eutrófico plíntico textura média/argilosa A moderado e proeminente fase concrecionária + CHERNOSSOLO ARGILÚVICO Órtico abrúptico textura média/argilosa, todos fase floresta subcaducifólia relevo suave ondulado e ondulado.

SXe2 (7)- Assoc. de: PLANOSSOLO HÁPLICO Eutrófico solódico textura arenosa e média/média e argilosa A moderado fase relevo suave ondulado e ondulado + NEOSSOLOS LITÓLICOS Eutróficos textura média A moderado e chernozêmico fase pedregosa e rochosa relevo suave ondulado a forte ondulado substrato gnaisse + CHERNOSSOLO ARGILÚVICO Órtico abrúptico textura média/argilosa fase relevo 
suave ondulado e ondulado, todos fase floresta caducifólia.

SXe3 (9)- Assoc. de: PLANOSSOLO HÁPLICO Eutrófico solódico textura arenosa e média/média e argilosa fase relevo plano e suave ondulado + NEOSSOLOS LITÓLICOS

Eutróficos textura arenosa e média fase pedregosa e rochosa relevo suave ondulado e ondulado substrato gnaisse, ambos A fraco e moderado fase caatinga hipoxerófila.

EK1 (3)- Assoc. de: ESPODOSSOLO CÁRBICO Órtico espessarênico + ARGISSOLO AMARELO Distrófico fragipânico textura média/argilosa + ARGISSOLO ACINZENTADO Distrófico abruptico fragipânico arenosa/média, todos A moderado fase cerrado e floresta subperenifólia relevo plano.

GX1 (8)- Assoc. de: GLEISSOLOS HÁPLICOS Distróficos indiscriminados textura indiscriminada + ORGANOSSOLOS, ambos fase relevo plano.

GS1 (10)- Complexo de: GLEISSOLOS SÁLICOS + GLEISSOLOS TIOMÓRFICOS, ambos textura indiscriminada + NEOSSOLO QUARTZARÊNICO Hidromórfico, todos fase relevo plano.

RQo1 (5)- Assoc. de: NEOSSOLO QUARTZARÊNICO Órtico típico A fraco + ESPODOSSOLO FERROCÁRBICO Órtico solódico textura arenosa A fraco e moderado, ambos fase campo e floresta perenifólia de restinga relevo plano.

RU1 (7)- Assoc. de: NEOSSOLOS FLÚVICOS Eutróficos e Distróficos textura indiscriminada A fraco e moderado + GLEISSOLOS HÁPLICOS indiscriminados, ambos fase relevo plano.

RLe1 (1)- NEOSSOLOS LITÓLICOS Eutróficos textura média A moderado fase pedregosa e rochosa, floresta caducifólia relevo montanhoso e forte ondulado substrato gnaisse e granito.

RLed1 (1)- NEOSSOLOS LITÓLICOS Eutróficos e Distróficos textura arenosa e média A moderado e proeminente fase pedregosa e rochosa, floresta caducifólia relevo suave ondulado a forte ondulado substrato gnaisse e quartzito.

A Geomorfologia da área de estudo também apresenta grande variabilidade resultante dos fatores climáticos e ambientes. As unidades de mapeamento e as notas de risco de salinização entre parênteses seguem abaixo:

Encosta Estrutural (2)- Área onde são freqüentes os declives iguais ou superiores a $30 \%$, correspondendo a todo "front" da encosta. A Rede Hidrográfica se adaptando à estrutura. As altitudes variam de 100 a 300 metros. O relevo da encosta é conseqüência da erosão diferencial, cuja evolução é comandada por fatores estruturais e morfológicos possuindo dinamismo próprio. Há um forte escoamento superficial ou subsuperficial da água, através de quedas d'água e corredeiras. A infiltração é menos intensa, que em especial com ausência de cobertura vegetal. A erosão dá-se na forma de anfiteatros, sulcos e voçorocas.

Terraço Marinho (10)- Feição ambiental gerado por processos deposicionais marinhos. Estão situados em estuários, tendo vegetação relacionada a solos arenosos ou areno-argilosos.

Restinga (7)- Faixa de areia depositada paralelamente ao litoral, graças ao dinamismo das águas oceânicas e continentais (fluvial).

Vale Fluvial (6)- Feição fluvial associada à drenagem. Apresenta tamanho e aspectos variados. Nos vales, a sucessão de fases de acumulação e de entalhamento pode gerar terraços fluviais.

Tabuleiro Dissecado (3)- Superfície tabular dissecado por vales fluviais. Os tabuleiros apresentam topografia plana, sedimentar e de baixa altitude. Os sedimentos transportados dos tabuleiros se depositam nos terraços coluvionar, marinho e aluvionar.

Pediplano Dissecado (8)- Processo de aplainamento de superfícies do Globo 
Terrestre, submetidas a clima árido ou semi-árido. Nos pediplanos encontram-se relevos residuais (inselbergues). $\mathrm{O}$ relevo é ondulado ou suave ondulado.

Inselbergues (0)- Elevações de clima árido. Considera-se esta feição como resíduos da pediplanação.

Terraço Coluvionar Associado à Pediplano (9)- Superfície de deposição, mais próxima do vale fluvial. Recebe sedimentos provenientes dos pediplanos e encostas estruturais. Relevo plano ou suave ondulado.
Interflúvio Estrutural Dissecado (1)- Na região de estudo corresponde aos topos das colinas estruturais. As altitudes variam de 300 a 600 metros.

Cordões Arenosos (7)- Superfície de deposição, mais próximas do Oceano. Englobam o ecossistema praia.

A Geologia da Bacia do Rio Coruripe de maneira similar à Pedologia e a Geomorfologia também apresentou grande variabilidade, como é apresentado no Quadro 1.

Quadro 1. Geologia da Bacia do Rio Coruripe e nota do risco de salinização (NRS).

\begin{tabular}{|c|c|c|c|c|}
\hline Era & Período & Unidade & Litologia & $\begin{array}{c}\text { Símbolo } \\
\text { (NRS) }\end{array}$ \\
\hline \multirow{3}{*}{ 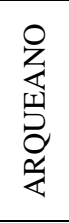 } & \multirow{3}{*}{ - } & $\begin{array}{c}\text { Seqüência de } \\
\text { Gnaisses Bandados }\end{array}$ & $\begin{array}{l}\text { Paraganisses, migmatitos, mica-xistos, mármores, rochas } \\
\text { calcissilicáticas, quartzitos, anfibolitos e ortognaisses. }\end{array}$ & Agn (5) \\
\hline & & $\begin{array}{l}\text { Complexo Jirau do } \\
\text { Ponciano }\end{array}$ & $\begin{array}{c}\text { Ortognaisses tonalíticos, dioríticos, monzoníticos, } \\
\text { granodioníticos e graníticos }\end{array}$ & A $\gamma \mathrm{j}(5)$ \\
\hline & & $\begin{array}{l}\text { Ortognaisses Tipo } \\
\text { Belém }\end{array}$ & Ortognaisses graníticos, sieno-graníticos e migmatitos & A $\gamma b(5)$ \\
\hline \multirow{9}{*}{ 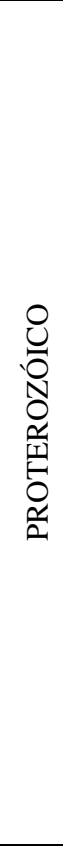 } & \multirow{6}{*}{ Grupo Jaramantaia } & $\begin{array}{c}\text { Formação Santa } \\
\text { Cruz }\end{array}$ & Quartzitos & Psc (2) \\
\hline & & $\begin{array}{l}\text { Domínio Rio } \\
\text { Coruripe }\end{array}$ & $\begin{array}{l}\text { Anfibolito, granulito, kinzigito, quartzito ferrífero, } \\
\text { carbonático e ortoderivado, migmatitos paraderivados, } \\
\text { granada-biotita-ganaisses e granada-biotita-xistos }\end{array}$ & Pc (5) \\
\hline & & $\begin{array}{l}\text { Quartzitos do } \\
\text { Domínio Rio } \\
\text { Coruripe }\end{array}$ & Quartzitos micáceos, foliados e ferruginosos & Pcq (2) \\
\hline & & $\begin{array}{l}\text { Formações } \\
\text { Ferríferas do } \\
\text { Domínio Rio } \\
\text { Coruripe }\end{array}$ & $\begin{array}{l}\text { Formações ferríferas constituídas por magnetita, } \\
\text { hematita, quartzo e presença de grunerita e hipertênio. }\end{array}$ & $\operatorname{Pcf}(2)$ \\
\hline & & $\begin{array}{l}\text { Mármores e Rochas } \\
\text { calcissilicatadas da } \\
\text { Domínio Rio } \\
\text { Coruripe. } \\
\end{array}$ & $\begin{array}{l}\text { Mármores calcíticos, dolomíticos, rochas } \\
\text { calcissilicatadas, }\end{array}$ & $\begin{array}{l}\text { Pcm e Pcc } \\
\text { (7) }\end{array}$ \\
\hline & & $\begin{array}{c}\text { Domínio Traipu- } \\
\text { Jaramantaia }\end{array}$ & Metaritmitos, micaxistos e paragnaisses & Pt (5) \\
\hline & \multirow{3}{*}{$\begin{array}{l}\text { Rochas Plutônicas } \\
\text { relacionadas à } \\
\text { evolução } \\
\text { Proterozóica }\end{array}$} & $\begin{array}{l}\text { Complexo Máfico- } \\
\text { Ultramáfico }\end{array}$ & $\begin{array}{c}\text { Piroxenitos, magnetitos, anfibolitos, noritos, gabros } \\
\text { noríticos, gabros e anortositos. }\end{array}$ & $\mathrm{P} \delta(6)$ \\
\hline & & $\begin{array}{l}\text { Granitos tipo Bela } \\
\text { Aurora }\end{array}$ & Granodioritos, sieno-granitos e granitos. & $\mathrm{P} \gamma 2(5)$ \\
\hline & & Rochas Sieníticas & Rochas sieníticas & $\mathrm{P} \lambda(5)$ \\
\hline \multirow{4}{*}{ 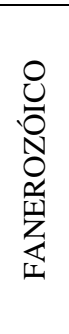 } & \multirow{4}{*}{ Cenozóico } & Formação Penedo & Arenitos, folhelhos, siltitos, calcáreo argilosos impuros & Kро (2) \\
\hline & & Grupo Barreiras & $\begin{array}{l}\text { Litótipos clásticos continentais com matriz } \\
\text { predominantemente argilosa, arenitos, siltitos e níveis } \\
\text { lateríticos }\end{array}$ & TQb (2) \\
\hline & & $\begin{array}{l}\text { Coberturas } \\
\text { Detríticas }\end{array}$ & $\begin{array}{l}\text { Depósitos conglomeráticos com seixos de quartzo e } \\
\text { fragmentos de rocha numa matriz arenosa }\end{array}$ & Qd (2) \\
\hline & & $\begin{array}{l}\text { Depósitos } \\
\text { Aluvionares e } \\
\text { Marinhos }\end{array}$ & $\begin{array}{l}\text { Sedimentos marinhos arenosos; aluviais de granulometri } \\
\text { variada e turfáceos }\end{array}$ & Qa (8) \\
\hline
\end{tabular}




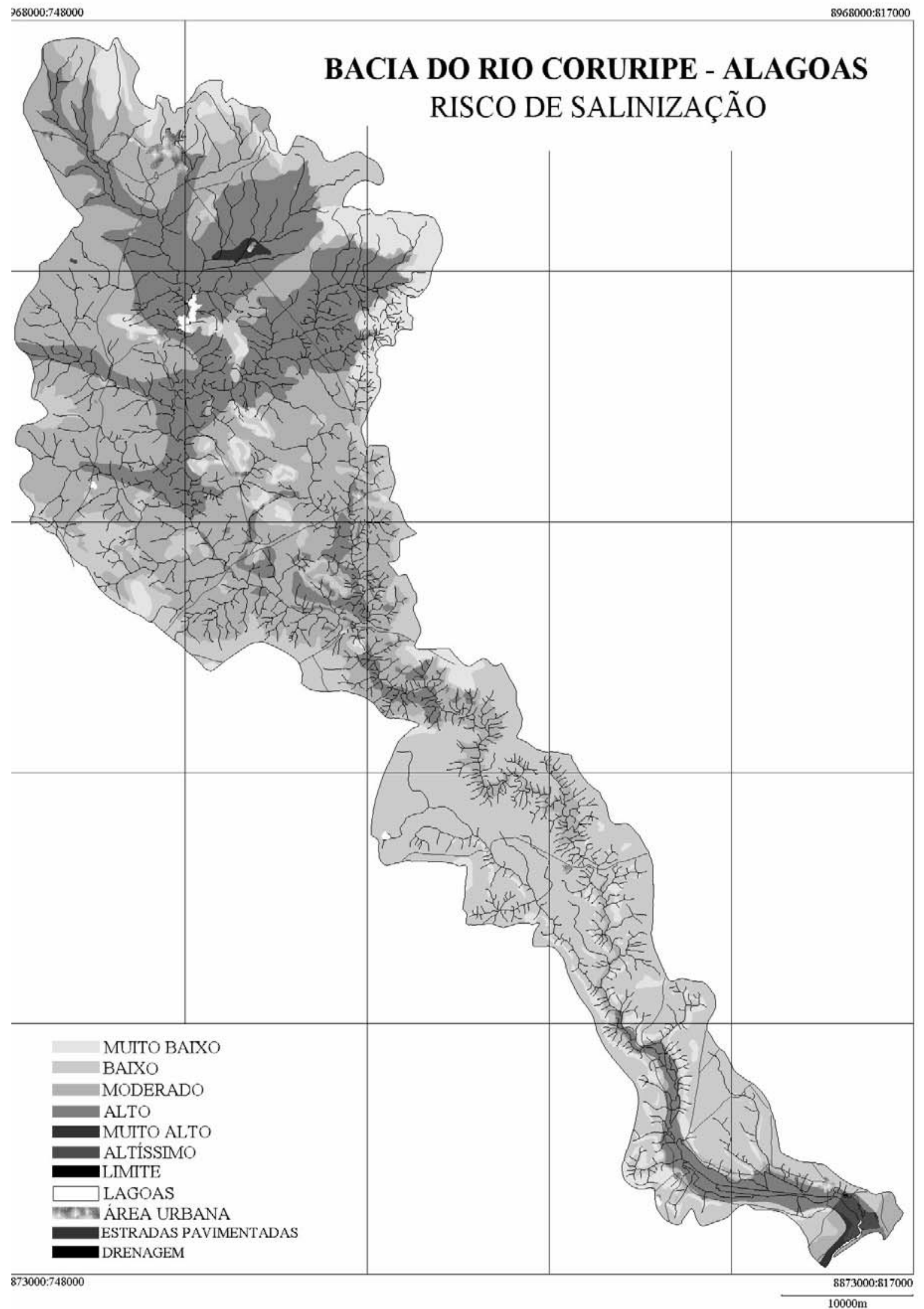

Figura 1. Risco de salinização das terras da Bacia do Rio Coruripe, AL.

A figura 1 apresenta o mapa de riscos de salinização da Bacia do Rio Coruripe, toda a bacia apresenta uma área de $1650,7 \mathrm{~km}^{2}$. A classe de risco considerada muito baixa corresponde a 130,33 $\mathrm{km}^{2}$ que é $7,9 \%$ da área; a classe ENGEVISTA, v. 6, n. 3, p. 86-98, dezembro 2004 considerada baixo corresponde a 371,8 $\mathrm{km}^{2}$ e a $22,5 \%$ da bacia. As duas classes apresentam predominantemente os seguintes solos: Latossolos, Argissolos, Nitossolos e Neossolos Litólicos, que apresentam boa drenagem e argila de 
atividade baixa; quanto à geomorfologia essas áreas se apresentam em condições de relevos movimentados, como, interflúvios, encostas estruturais e inselbergs, ou em ambientes com relevo plano ou suave ondulado nos tabuleiros costeiros. Quanto à litologia a maior parte se localiza associada a sedimentos como os do Grupo Barreiras ou ao Domínio Rio Coruripe associado a rochas do tipo kinzigitos e migmatitos, algumas vezes surgem quartzitos.

A classe com risco moderado representa cerca de $30,5 \%$ da bacia, localiza-se principalmente na região do agreste nos pediplanos dissecados e vales fluviais, os solos predominantes são Latossolos, Argissolos e Planossolos, todos eutróficos, em ambiente com água de salinidade elevada. A litologia varia de sedimentos detríticos a rochas tipo gnaisses e kinzigitos. Essas regiões sofrem maior risco de sofrerem salinilização caso sejam utilizadas com agricultura irrigada mal manejada, ou com águas de má qualidade, seja pela natureza eutrófica dos solos e pelas águas com elevada salinidade.

As áreas classificadas com alto risco de salinização ocupam cerca de $36,8 \%$ da bacia. Localizam-se em duas regiões diferenciadas da bacia: a primeira na região de cota mais baixa, no vale fluvial, nos terraços e várzeas do Rio Coruripe, associada a solos mal ou muito mal drenados, da classe dos Gleissolos e Organossolos, em ambiente de Depósitos do Quaternário; ou na região do agreste com predomínio de Planossolos com caráter solódico, e outros solos com argila de atividade alta e drenagem moderada ou imperfeita, sendo a litologia predominante de rochas ácidas, ocorrendo rochas sieníticas.

A classe considerada como muito alto risco de salinização ocorre somente em $0,4 \%$ da bacia e está associada a Gleissolos, Espodossolos e Neossolos Quartzarênicos hidromórficos, podendo apresentar caráter sálico ou tiomórfico, formados de sedimentos quaternários marinhos na planície costeira e em restingas; ou na região do agreste em área de rochas calcárias e Planossolos com horizonte $\mathrm{B}$ de textura argila de alta atividade, imperfeitamente drenados e caráter solódico, tendo elevada concentração de cátions salinos solúveis como sódio e magnésio.

$\begin{array}{rrrr}\text { A } & \text { classe } & \text { considerada com } \\ \text { altíssimo } & \text { risco } & \text { de salinização }\end{array}$ corresponde a $0,3 \%$ da bacia, próxima a sua foz, é formada em sua totalidade de solos muito mal drenados, que sofrem influência das marés, em ambientes de mangue, com caráter sálico e tiomórfico. Áreas que devem ter como principal uso a preservação ambiental.

\section{CONCLUSÕES}

A metodologia da média ponderada aplicada ao SIG foi eficiente na elaboração do mapa de risco de salinização com base na pedologia, geomorfologia e geologia. O mapa de risco de salinização da Bacia do Rio Coruripe pode ser utilizado como material básico para a elaboração de zoneamentos e em planejamento agroambiental em escala regional.

O uso do geoprocessamento e tecnologia de SIG, neste caso o SAGA/UFRJ, tornou disponível diversas variáveis que permitiram equacionar o processo de tomada de decisão. Os produtos oriundos da Base de Dados Georreferenciada e das Avaliações Ambientais podem contribuir como apoio ao desenvolvimento e aplicação de medidas mitigadoras dirigidas a esta questão ambiental em particular.

\section{AGRADECIMENTOS}

À COHIDRO pelo financiamento do trabalho.

\section{BIBLIOGRAFIA}

AB'SABER, NA. A problemática da desertificação no Brasil intertropical. Geomorfologia, Inst. de Geografia USP. SP/ 53: 1-20.

CPRM. Projeto Baixo São Francisco / Vaza-barris, folhas SC.24-X-D e SC.24Z-B. 1977. 
CPRM. Programa Levantamentos Geológicos do Brasil, Arapiraca folha SC.24-X-D-V, AL 1995.

ACCIOLY L. J. O. Degradação do solo e desertificação no Nordeste do Brasil. Boletim Informativo Sociedade Brasileira de Ciência do Solo, Viçosa, MG, v. 25, n. 1, p. 23-25. jan./mar. 2000.

\section{AMBIENTEBRASIL. Desertificação.} s.d. Disponível em: $<$ http://www.ambientebrasil.com.br/com poser.php3?base=./agropecuario/index.ht ml\&conteudo=./agropecuario/click/desert ificacao.html>. Acesso em: 19 jan. 2004.

BASTOS, E. J. B.; SOUZA, R. A. F.; ALVALÁ, R. C. S. Emissividade da superfície sobre Brasil a partir de observações do SSM/I em $19 \mathrm{GHz}$ e 85 GHz. Brazilian Journal of Geophysics. v. 18, n. 2, p. 147-158, 2000.

CARDOSO, A.; POTTER, R. O.; DEDECEK, R. A. Estudo comparativo da degradação de solos pelo uso agrícola no noroeste do Paraná. Pesquisa agropecuária brasileira, Brasília, v. 27, n. 2, p. 349-353, 1992.

COIMBRA, R. M. Informe Nacional 2002, 2002. Disponível em: <http://www.mma.gov.br/port/srh/index.c fm>. Acesso em: 02 fev. 2004.

CONAMA. Resolução n⿳2028, de 22 de dezembro de 1997. Disponível em: <http://www.mma.gov.br/port/conama/re s/res97/res23897.html>. Acesso em: 27 jan. 2004

CORRÊA, A. Fazedores de Desertos. $1999 . \quad$ Disponível em: $<$ http://www.cnps.embrapa.br/search/pla nets/coluna08/coluna08.html>. Acesso em: 04 fev. 2004.

EMBRAPA. Centro de Pesquisa Agropecuária do Trópico Semi-Árido. Salinidade e drenagem. s.d. Disponível em:

$<$ http://www.cpatsa.embrapa.br/salinidad e.html>. Acesso em: 03 fev. 2004.

EMBRAPA. Centro Nacional de Pesquisa de Solos. Sistema brasileiro de classificação de solos. Rio de Janeiro: Embrapa Solos, 1999. 412 p.
EMBRAPA. Atlas do Meio Ambiente do Brasil. Brasília, Ed. Terra Viva, 1994.

FARIA, A L L . Geoprocessamento na Bacia Hidrográfica do Ribeirão do Espírito Santo - Juiz de Fora(MG): Um Diagnóstico Ambiental das áreas de Susceptibilidade à Erosão e de Potencial para Pecuária de Leite. Dissertação de Mestrado apresentada ao Curso de Mestrado em Ciências Ambientais e Florestais da UFRRJ. UFRRJ 2000.

FREITAS, C. A.; GOULART, D. D.; ALVES, F. D. O processo de arenização no Sudoeste do Rio Grande do Sul: uma alternativa para o seu desenvolvimento sócio-econômico. In: $1^{\circ}$ Encontro de Economia Gaúcha, 2002. Disponível em: $<$ http://www.fee.rs.gov.br/eeg>. Acesso em: 02 fev. 2004.

GOMES, E.G.; ESTELLITA LINS, M.P. Integrating Geographical Information Systems and Multi-criteria Methods: a case study. Annals of Operations Research, v.116, p. 243-269, 2002.

JANKOWSKI, P. Integrating geographical information systems and multiple criteria decision-making methods. International Journal of Geographical Information Systems, v. 9, n. 3, p. 251-273. 1995.

MACÊDO, L. S.; SANTOS, J. B. Efeito da aplicação de água salina sobre os solos irrigados na bacia Sucuru/Sumé, PB. Pesquisa agropecuária brasileira, Brasília, v. 27, n. 6, p. 915-922, jun. 1992.

MAINGUET, M.; SILVA, G. G. Desertification and drylands development: What can be done?. Land Degradation \& Development. v. 9, p. 375-382, 1998.

MALCZEWSKI, J. GIS and Multicriteria Decision Analysis. New York: John Wiley \& Sons, 1999.

MINISTÉRIO DO MEIO AMBIENTE. Desertificação no Brasil. Disponível em: <http://www.mma.gov.br/port/srh/index.c fm>. Acesso em: 03 fev. 2004. 
MINISTÉRIO DO MEIO AMBIENTE. Agenda 21 brasileira. Disponível em: <http://www.mma.gov.br/port/se/agen21/ >. Acesso em: 07 out. 2004.

\section{MUZILLI, O. Degradação e} recuperação do solo sob uso agrícola: O caso do estado do Paraná. Disponível em: $\quad<$ http://www.cemacufla.com.br/trabalhospdf/palestras/palestr a\%200smar\%20muzilli.pdf $>$. Acesso em: 26 jan. 2004.

OLIVEIRA, L. B. Avaliação da salinização dos solos sob caatinga do Brasil. In: ALVARES, V. H.; FONTES, L. E. F.; FONTES, M. P. F. (ed.). O solo nos grandes domínios morfoclimáticos do Brasil e o desenvolvimento sustentado. Viçosa, MG. Sociedade Brasileira de Ciência do Solo, UFV, DPS, 1996. p. 113-123.

OLIVEIRA, L. B. et al. A. Inferências pedológicas aplicadas ao perímetro irrigado de Custódia, PE. Pesquisa agropecuária brasileira, Brasília, v. 37, n. 10, p. 1477-1486, out. 2002.

OLIVEIRA, M. O Nordeste no mapa mundi da desertificação. Boletim Informativo Sociedade Brasileira de Ciência do Solo, Viçosa, MG, v. 25, n. 1, p. 18-20. jan./mar. 2000.

RAMALHO FILHO, A.; BEEK, K.J. Sistema de Avaliação da aptidão agrícola das terras. 3. ed. Rio de Janeiro: Embrapa Solos, 1995. 65 p.

SAADI, A. Os sertões que viram desertos. Boletim Informativo Sociedade Brasileira de Ciência do Solo. Viçosa, MG, v. 25, n. 1, p. 10-17. jan./mar. 2000.

SCHOFIELD, R. V.; KIRKBY, M. J. Application of salinization indicators and initial development of potential global soil salinization under climatic change. Global Biochemical Cycles. v. 17, n. 3, 1078, p. 4.1-4.13, 2003.

SCHUMACHER, M. V. "Deserto de alegrete" Florestas, uma alternativa de controle? Boletim Informativo Sociedade Brasileira de Ciência do Solo. Viçosa, MG, v. 25, n. 1, p. 21-23. jan./mar. 2000.

ENGEVISTA, v. 6, n. 3, p. 86-98, dezembro 2004
SILVA, M. S. L. et al. Exploração agrícola em barragem subterrânea. Pesquisa agropecuária brasileira, v. 33, n. 6, p. 975-980, jun. 1998.

SYMEONAKIS, E.; DRAKE, N. Monitoring desertification and land degradation over sub-Saharan Africa. International Journal of remote sensing. v. 25, n. 3, p. 573-592. 10 fev. 2004.

SUERTEGARY, D.M.A. Desertificação: Recuperação e Desenvolvimento Sustentável. In: CUNHA, S.B. \& GUERRA, AJ.T. Geomorfologia e Meio Ambiente. RJ: Bertrand Brasil, 1996.

TORRION, J. A. Land degradation detection, mapping and monitoring in the lake Naivasha Basin, Kenya, 2002. $104 \mathrm{f}$. Thesis (Master of Sciencs in Natural Resource Management) International Institute for Geoinformation Science and Earth Observation, Enschede, The Netherlands, 2002.

XAVIER-DA-SILVA,J.

Geoprocessamento e Análise Ambiental. Revista Brasileira de Geografia. Rio de Janeiro, 54 (3) 1992. p 47-61. 